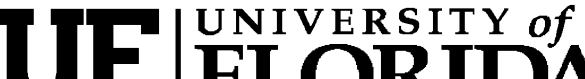 FLORIDA \\ IFAS Extension
}

\section{Livestock Fence Construction ${ }^{1}$}

\section{Reyna Speckmann and Jeff Steele ${ }^{2}$}

Reliable, durable fence construction is a priority for livestock operations. Inadequately constructed fence and fence failures not only demand additional labor, they also create potential safety and ethical concerns. While Florida's Fence and Property laws do not require livestock owners to build or maintain fence, landowners may be civilly and criminally liable if livestock stray onto public roads.

The materials and assembly guides provided below are standard operating procedures practiced at the UF/IFAS Range Cattle Research and Education Center in Ona, FL.

\section{Tool List}

\section{New Fence Construction}

- Shovel

- Post Hole Diggers

- Bolt Cutters

- Fence Pliers

- Sledge Hammer
- Tamp Stick

- Come Along \& Wire Dog

- Hatchet or Hammer

- Hand Saw

- Leather Gloves

- Additional Field Fence Tools

- Wire Twister

- Clamp-type Wire Stretcher

-10" Klein Lineman's Pliers

- Wire Unroller

\section{Barb-Wire Fence and Gap Repair}

- Fence Pliers

- Leather Gloves

- Hatchet or Hammer

- Post Hole Diggers 
- Hand Saw

- Bolt Cutters

- Ratchet-type Fence Jack

\section{Corner Brace}

\section{Materials}

(2) 6" to 8"x8' corner post

(1) $4 "$ x $6.5^{\prime}$ treated line post

40-penny galvanized nails

1 1/2" Fence Staples

\#9 Galvanized Brace wire (approx 17 1/2')

\section{Assembly}

- Dig initial corner post hole (approx 12" diameter $\mathrm{x}$ 4' deep)

- Drop corner post into hole

- Set height and position (level or plumb bob)

- 54" for barbwire

- 58-60" for field fence

- Backfill, tamping tightly after each shovelful to ensure a solid brace system

- Place line post on the ground to determine the location for the second brace post

- Dig second post hole and place second brace post

- Check post height using a level across post tops

- Drive a 40 penny nail halfway into each line post 12" from the top (approx the length of a hatchet handle) and remove nail heads

- Drive line post onto nails

- Slowly backfill, tamping tightly after each shovelful

- Install brace wire according to fence direction (up with the direction of pull)
- Set bottom staple approx 4" above the ground - Set top staple level with the top line of the brace post

- Run brace wire through bottom staple so that an even length of wire is on both sides of the staple

- Insert both cut ends of the brace wire through the top staple and pull tight

- Drive top staple to firmly hold brace wire - Loosely wrap excess cut-end wire around diagonal brace wire 3-4 times, followed by a minimum of 5 wraps pulled as tight as possible - Place uncoated plier handles between wires and twist until tight (approximately 10 turns)

- Use extreme caution when twisting wires with plier handles to avoid injury

CORNER BRACE ASSEMBLY

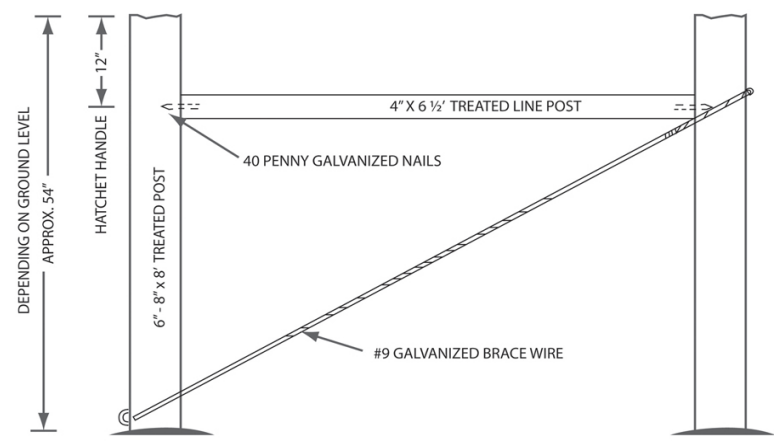

Figure 1. Corner Brace Assembly

\section{BRACE WIRE ASSEMBLY}

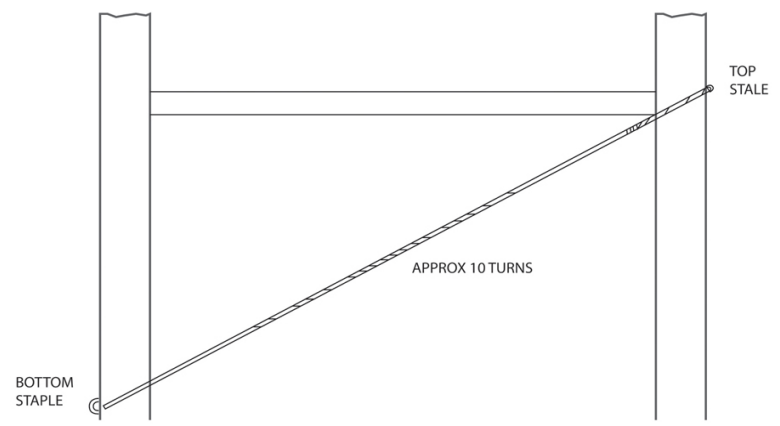

Figure 2. Brace Wire Assembly 


\section{BRACE WIRE DETAIL}

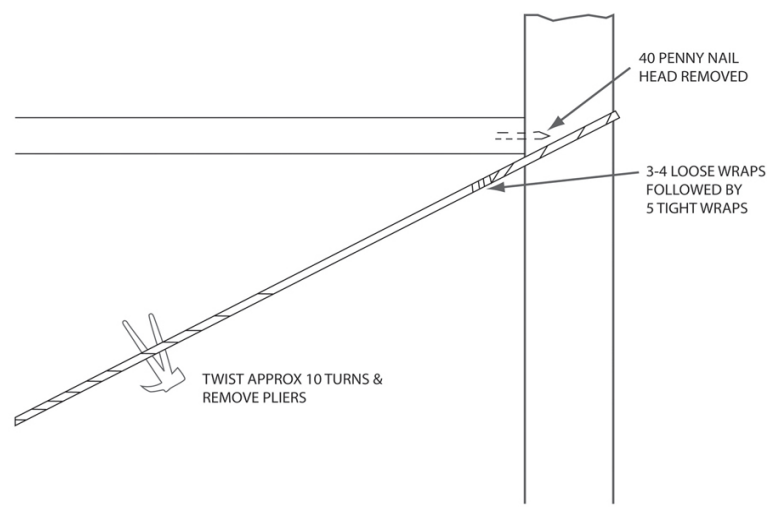

Figure 3. Brace Wire Detail

\section{Barbwire}

\section{Materials}

4" x $6.5^{\prime}$ treated line post

1 1/2" Fence Staples

Gaucho (class 3) barbwire

\section{Assembly}

- Attach bottom wire between the corner braces to serve as a guide line

- Pay out wire on pressure side of the fence

- Drive staples on a slant (as opposed to vertical or horizontal; see diagram)

- Dig line post holes 24-30" deep, spaced 15' apart

- Set posts and leave loose

- Unroll and fasten wire one strand at a time, starting with the top strand

- Drive staples on a slant (as opposed to vertical or horizontal; see diagram)

- Attach top strand 3 1/2 - 4" (approx hand width) from post top (5 strand) or 8 " from post top (4 strand)

- Wrap strand around post and splice back on itself

- Use top strand to achieve desired line post height and backfill holes
- Attach remaining strands

- See diagram for four and five strand spacing FOUR STRAND WIRE SPACING

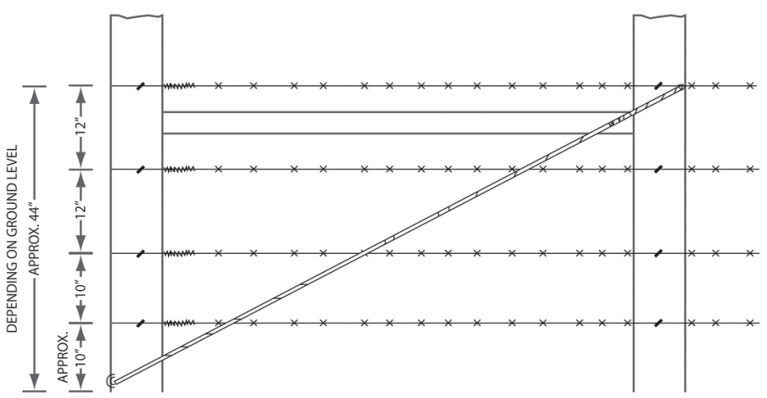

Figure 4. 4 Strand Spacing

FIVE STRAND WIRE SPACING

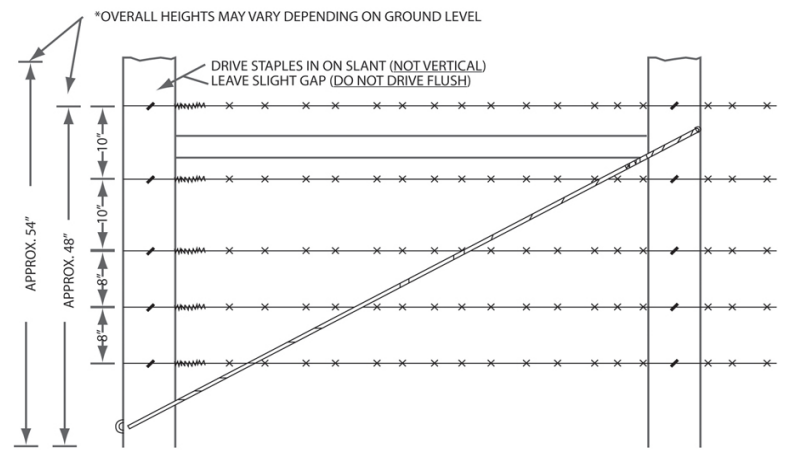

Figure 5. 5 Strand Spacing

Field Fence

Materials

4" x 6.5' treated line post

1 1/2" Fence Staples

5" Gaucho (class 3) barbwire

48" Field fence

\section{Assembly}

- Attach bottom gaucho wire between the corner braces to serve as a guide line

- Pay out wire on pressure side of the fence

- Drive staples on a slant (as opposed to vertical or horizontal; see diagram)

- Dig line post holes 24-30" deep, spaced 15' apart 
- Set posts and leave loose

-Wrap field fence around corner post and staple to secure

- Pay out wire on pressure side of the fence

- Set at height approximately 3 " off the ground

- If it is necessary to splice rolls, overlap one full square from each roll and use a wire twister to tightly wrap cut ends

- Pull fence tight using a wire-puller and a come-along. This can be achieved by using two come-alongs set top and bottom or by running a chain from the bottom of a clamp, through the come-along, and back to the top to the clamp.

- Staple wire to corner post and twist off free ends

- Set line post height (approx 6" of post above field fence)

- Staple field fence and bottom gaucho wire to line posts to secure

- Add top gaucho wire, 2" above field fence, if necessary

FIELD FENCE ASSEMBLY

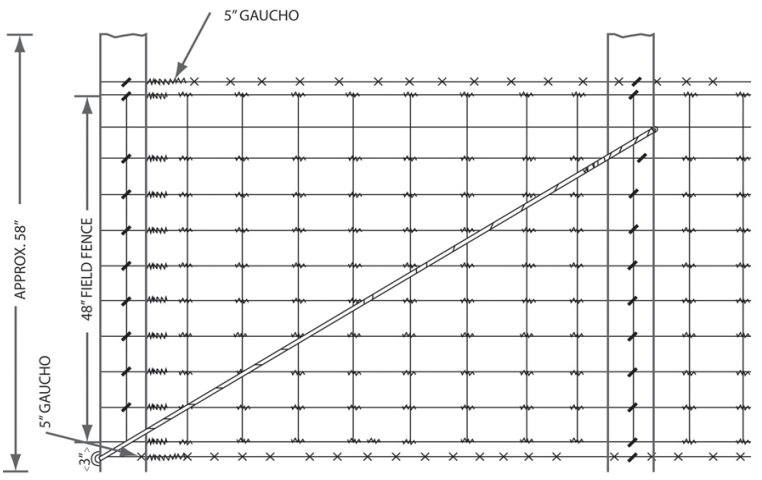

Figure 6. Field Fence Assembly

\section{Gap Construction}

- Select straight gap post and cut height to match brace post

- Secure gap wires to brace and gap posts, matching wire spacing of the fence

- Wrap gap side longer than normal in case gap post needs to be replaced
FIELD FENCE SPLICE DETAIL

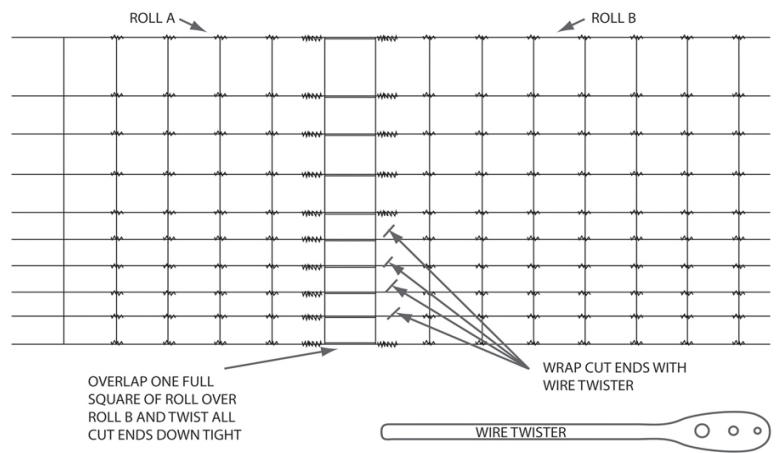

Figure 7. Field Fence Splice

- Install 3-5 wire stays, spaced evenly across gap

- Use wire stays to make top and bottom latches

- One staple in top

- Bottom stapled solid

\section{GAP CONSTRUCTION}

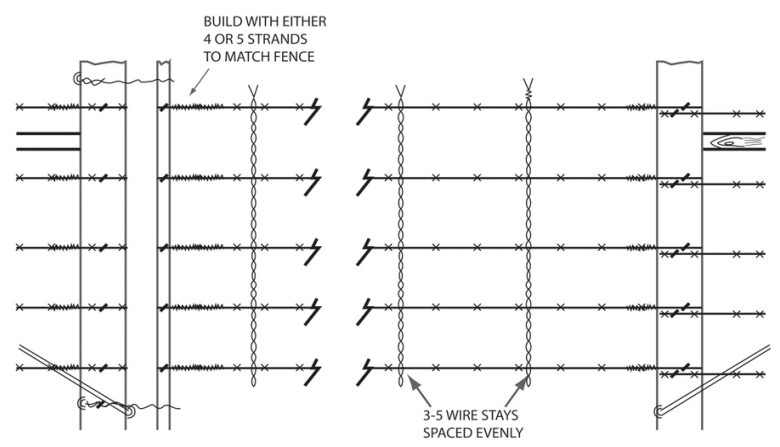

Figure 8. Gap Assembly

\section{Barbwire Repair}

- Select a piece of splice wire approximately 4' longer than the gap in the existing, broken strand

- Attach the splice wire to the left side of the existing strand

- Overlap two or more barbs and twist tightly

- Insert and clamp the right broken strand into the fence jack

- Fully open fence jack and attach new splice wire into left side and clamp 
- Jack wires until tight

-Wrap new wire around existing right side strand

- Overlap two or more barbs and twist tightly

-Wrap existing fence tag ends around splice wire

- Replace any missing staples in adjacent posts

\section{SPLICING BROKEN WIRES}
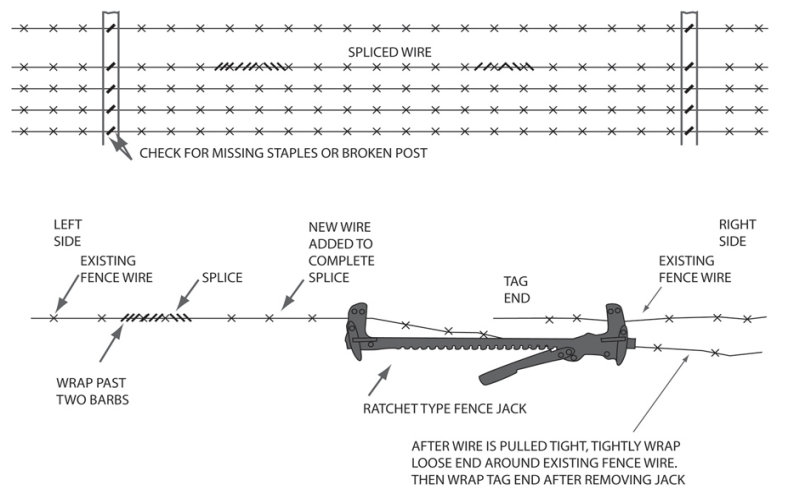

Figure 9. Barbwire Repair 